\title{
Foreign body cutaneous granuloma associated with a rose thorn: dermoscopy will tell you more
}

\section{Ziarniniak typu ciała obcego spowodowany kolcem róży i rola dermoskopii w diagnostyce schorzenia}

\author{
Anna Płaszczyńska, Martyna Sławińska, Roman J. Nowicki, Michał Sobjanek \\ Department of Dermatology, Venereology and Allergology, Faculty of Medicine, Medical University of Gdansk, Gdansk, Poland \\ Katedra i Klinika Dermatologii, Wenerologii i Alergologii, Wydział Lekarski, Gdański Uniwersytet Medyczny, Gdańsk, Polska \\ Dermatol Rev/Przegl Dermatol 2021, 108, 426-428 \\ DOI: https://doi.org/l0.51|4/dr.2021.113161
}

\begin{abstract}
A 64-year-old woman presented with a reddish nodule with a black center which occurred around 2 months before, after gardening (figs. 1 A). Dermoscopy showed a linear, cone-shape dark structure surrounded with red structureless areas, polymorphic vessels and small erosions (figs. $1 \mathrm{~B}, \mathrm{C}$ ). A meticulous enquiry on her gardening work along with dermoscopic assessment, made a thorn of the rose associated cutaneous foreign body granuloma the most possible diagnosis. After administering local anesthesia, the plant thorn was removed, leading to clinical improvement (figs. $1 \mathrm{D}-\mathrm{F}$ ).
\end{abstract}

Foreign body cutaneous granuloma (FBCG) is a chronic inflammatory process, which may be induced by different factors, including but not limited to ingrowing hairs, surgical sutures, pencil cores, tattoo pigments, glass, cosmetic fillers or plant thorns [1, 2]. It usually presents as an asymptomatic or painful/ itchy pink-reddish nodule, papule or plaque, which becomes fibrotic over time. Clinical diagnosis may sometimes be challenging, especially when the patient does not remember the disease onset or possible inducing events.

Dermoscopy is an auxiliary tool to diagnose FBCG and - as presented - may be particularly useful in visualization of the foreign body within the lesion. Dermoscopic findings of FBCG seem to be variable - pinkish/reddish structureless areas, linear vessels, scales, and scar-like white areas have been described. Interestingly, in most of the described cases, causative factors could not be directly visualized [1, 2]. As mentioned, FBCG commonly presents as an amelanotic nodule and thus may mimic other benign and malignant lesions [1]. In a case of a pencil core FBCG
Kobieta w wieku 64 lat zgłosiła się do Kliniki Dermatologii z powodu czerwonawego guzka z centralnym skupieniem barwnika. Zmiana pojawiła się 2 miesiące wcześniej, po wykonywaniu prac w ogrodzie (ryc. 1 A). W badaniu dermoskopowym uwidoczniono wydłużoną, stożkowatego kształtu strukturę barwnikową, otoczoną czerwonym obszarem bezstrukturalnym z widocznymi naczyniami polimorficznymi i towarzyszącymi drobnymi nadżerkami (ryc. 1 B, C). Na podstawie skrupulatnie zebranych od pacjentki informacji o wykonywanych pracach ogrodniczych oraz wyników badania dermoskopowego za najbardziej prawdopodobne rozpoznanie uznano ziarniniaka skóry spowodowanego przez ciało obce (kolec róży). Po zastosowaniu znieczulenia miejscowego kolec usunięto, uzyskując poprawę kliniczną (ryc. $1 \mathrm{D}-\mathrm{F}$ ).

Ziarniniak skóry spowodowany przez ciało obce (foreign body cutaneous granuloma - FBCG) jest przewlekłym procesem zapalnym, który może być wywołany przez różne czynniki, takie jak wrastające włosy, nici chirurgiczne, grafit z ołówka, pigmenty do wykonywania tatuaży, szkło, wypełniacze kosmetyczne lub kolce roślin [1, 2]. Zazwyczaj ma postać bezobjawowego lub bolesnego albo swędzącego guzka, grudki lub blaszki o barwie różowo-czerwonawej, z czasem ulegających zwłóknieniu. W niektórych przypadkach rozpoznanie kliniczne może być trudne, zwłaszcza gdy pacjent nie pamięta początku choroby lub nie potrafi jej powiązać z żadnym konkretnym zdarzeniem.

W diagnostyce FBCG pomocniczą rolę odgrywa dermoskopia. Jak wskazuje przedstawiony przypadek, metoda ta może być szczególnie przydatna przy wizualizacji ciała obcego w obrębie zmiany. Obraz 

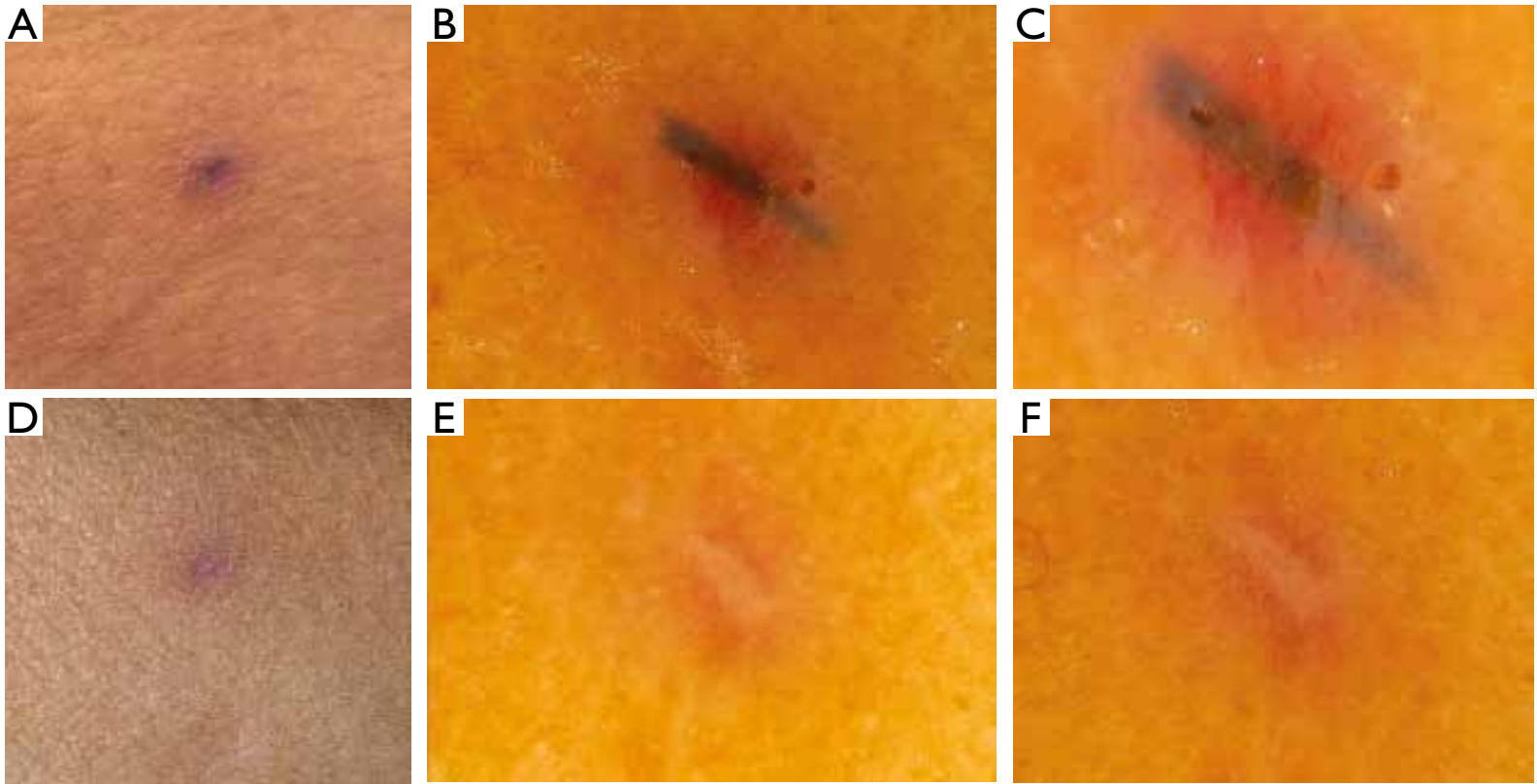

Figure I. A - Clinical presentation - a reddish nodule with black-gray area in the center of the lesion. B - Dermoscopy shows a cone-shape black structure surrounded with red structureless areas, polymorphic vessels and associated with small erosions, visible on dermoscopy as small yellow globules (FotoFinder videodermoscope, non-polarized dermoscopy, 20x magnification, ultrasound gel as immersion fluid). C - Dermoscopic presentation in larger magnification shows details of blood vessel morphology (FotoFinder videodermoscope, non-polarized dermoscopy, 70× magnification, ultrasound gel as immersion fluid). D - Clinical presentation - 2 weeks after removal of the rose thorn. $\mathbf{E}$ - Dermoscopy shows the scar surrounded with pinkish structureless areas (FotoFinder videodermoscope, non-polarized dermoscopy, $20 \times$ magnification, ultrasound gel as immersion fluid). F - Dermoscopic presentation in larger magnification shows the resolution of blood vessels visible before the rose thorn removal (FotoFinder videodermoscope, non-polarized dermoscopy, $70 \times x$ magnification, ultrasound gel as immersion fluid)

Rycina I. A - Obraz kliniczny - czerwonawy guzek z czarnoszarym obszarem w centrum zmiany. B - Badanie dermoskopowe uwidacznia centralnie umiejscowiony czarny obszar bezstrukturalny o kształcie stożka, otoczony czerwonym obszarem bezstrukturalnym i naczyniami polimorficznymi, wraz z towarzyszącymi drobnymi nadżerkami widocznymi w dermoskopii jako drobne żółte grudki (wideodermoskop FotoFinder, światło niespolaryzowane, powiększenie 20x, immersja przy użyciu żelu ultrasonograficznego). C - Obraz dermoskopowy w większym powiększeniu ukazuje szczegóły morfologii naczyń krwionośnych (wideodermoskop FotoFinder, światło niespolaryzowane, powiększenie 70x, immersja przy użyciu żelu ultrasonograficznego). D - Obraz kliniczny 2 tygodnie po usunięciu kolca róży. E - W obrazie dermoskopowym widoczna blizna otoczona przez różowe obszary bezstrukturalne (wideodermoskop FotoFinder, światło niespolaryzowane, powiększenie 20x, immersja przy użyciu żelu ultrasonograficznego). F - Obraz dermoskopowy w większym powiększeniu po usunięciu kolca róży pokazuje ustapienie widocznych wcześniej naczyń krwionośnych (wideodermoskop FotoFinder, światło niespolaryzowane, powiększenie 70×, immersja przy użyciu żelu ultrasonograficznego)

other blue lesions should also be considered among differential diagnoses [2]. In the presented case, the patient's history and the thorn of the rose visible on dermoscopic assessment was sufficient to make a decision about patient management. However, in any uncertainty, biopsy and histopathological assessment should be performed.

\section{CONFLICT OF INTEREST}

The authors declare no conflict of interest. dermoskopowy FBCG wydaje się dość zróżnicowany. W piśmiennictwo opisywano różowawo-czerwonawe obszary bezstrukturalne, naczynia o linijnym przebiegu, łuskę i białe obszary bezstrukturalne. Co ciekawe, w większości dotychczas opisanych przypadków nie udało się bezpośrednio uwidocznić czynnika sprawczego [1, 2]. Jak już wspomniano, FBCG często ma postać amelanotycznego guzka, który może przypominać inne zmiany skórne, o charakterze zarówno łagodnym, jak i złośliwym [1]. W przypadku FBCG wywołanego przez grafit ołówkowy w diagnostyce różnicowej należy uwzględnić inne zmiany o niebieskawym zabarwieniu [2]. W przedstawionym przypadku wywiad zebrany od pacjentki oraz kolec róży widoczny w badaniu dermoskopowym stanowiły wystarczające przesłanki do podjęcia decyzji o dalszym postępowaniu. W przypadkach wątpliwych 
u pacjentów należy dodatkowo wykonać biopsję i badanie histopatologiczne.

\section{KONFLIKT INTERESÓW}

Autorzy nie zgłaszają konfliktu interesów.

\section{References}

Piśmiennictwo

1. Conforti C., Dri A., Errichetti E., Zelin E., Zalaudek I., Di Meo N.: Dermoscopic features of foreign body cutaneous granuloma: a case series. Dermatol Pract Concept 2021, 11, e2021025.

2. Yoshikawa M., Kamiya T., Sumikawa Y., Uhara H.: Unique dermoscopic feature of a long-standing pencil core granuloma on the head. J Dermatol 2019, 46, e172-e173.

Received: 30.08 .2021

Accepted: 5.09.2021

Otrzymano: $30.08 .2021 \mathrm{r}$.

Zaakceptowano: 5.09.2021 r.

How to cite this article

Płaszczyńska A., Sławińska M., Nowicki R.J., Sobjanek M.: Foreign body cutaneous granuloma associated with a rose thorn: dermoscopy will tell you more. Dermatol Rev/Przegl Dermatol 2021, 108, 426-428. DOI: https://doi.org/10.5114/dr.2021.113161 